\title{
Serum Bilirubin Concentration is Associated with Left Ventricular Remodeling in Patients with Type 2 Diabetes Mellitus: A Cohort Study
}

\author{
Tomoaki Inoue $\cdot$ Noriyuki Sonoda $\cdot$ Shinsuke Hiramatsu $\cdot$ Shinichiro Kimura \\ Yoshihiro Ogawa · Toyoshi Inoguchi
}

Received: November 30, 2017 / Published online: January 15, 2018

(C) The Author(s) 2018. This article is an open access publication

\begin{abstract}
Introduction: Previous studies have shown that serum bilirubin concentration is inversely associated with the risk of cardiovascular disease. The relationship between serum bilirubin concentration and left ventricular geometry, however, has not been investigated in patients with diabetes mellitus.
\end{abstract}

Enhanced content To view enhanced content for this article go to http://www.medengine.com/Redeem/ 702DF06025BC37B3.

Electronic supplementary material The online version of this article (https://doi.org/10.1007/s13300018-0368-6) contains supplementary material, which is available to authorized users.

\section{T. Inoue $(\bowtie)$}

Department of Diabetes Mellitus and

Endocrinology, Tagawa Municipal Hospital,

Fukuoka, Japan

e-mail: tomo-i@intmed3.med.kyushu-u.ac.jp

T. Inoue $\cdot S$. Hiramatsu

Department of Diabetes Mellitus and

Endocrinology, Hamanomachi Hospital, Fukuoka, Japan

N. Sonoda $\cdot$ S. Kimura · Y. Ogawa · T. Inoguchi Department of Medicine and Bioregulatory Science, Graduate School of Medical Sciences, Kyushu University, Fukuoka, Japan

\section{Y. Ogawa}

Department of Molecular and Cellular Metabolism, Graduate School of Medical and Dental Sciences,

Tokyo Medical and Dental University, Tokyo, Japan
Methods: In this cohort study, 158 asymptomatic patients with type 2 diabetes mellitus without overt heart disease were enrolled. Left ventricular structure and function were assessed using echocardiography. Serum bilirubin concentration, glycemic control, lipid profile, and other clinical characteristics were evaluated, and their association with left ventricular geometry was determined. Patients with New York Heart Association Functional Classification greater than I, left ventricular ejection fraction less than 50\%, history of coronary artery disease, severe valvulopathy, chronic atrial fibrillation, or creatinine clearance less than $30 \mathrm{ml} / \mathrm{min}$, and those receiving insulin treatment, were excluded.

Results: Univariate analyses showed that relative wall thickness (RWT) was significantly correlated with diastolic blood pressure $(P=0.003)$, HbA1c $(P=0.024)$, total cholesterol $(P=0.043)$, urinary albumin $(P=0.023)$, and serum bilirubin concentration $(P=0.009)$. There was no association between left ventricular mass index and serum bilirubin concentration. Multivariate linear regression analysis showed that log RWT was positively correlated with diastolic blood pressure $(P=0.010)$ and that log RWT was inversely correlated with log bilirubin $(P=0.003)$. In addition, the patients with bilirubin less than $0.8 \mathrm{mg} / \mathrm{dl}$ had a higher prevalence of concentric left ventricular remodeling compared with those with bilirubin $0.8 \mathrm{mg} / \mathrm{dl}$ or more. 
Conclusion: Our study shows that the serum bilirubin concentration may be associated with the progression of concentric left ventricular remodeling in patients with type 2 diabetes mellitus.

Keywords: Bilirubin; Diabetes; Echocardiography; Left ventricular geometry

\section{INTRODUCTION}

Patients with diabetes mellitus are at increased risk for cardiovascular disease (CVD), which is the leading cause of diabetes-related morbidity and mortality [1]. Previous studies have reported that low serum bilirubin concentration is associated with an increased risk of CVD $[2,3]$. Conversely, higher serum bilirubin concentrations were associated with a decreased risk of CVD in a prospective study of serum bilirubin and CVD in the Framingham Offspring Study [4]. However, the relationship of serum bilirubin concentration to left ventricular geometry in patients with type 2 diabetes mellitus (T2DM) has not been extensively explored. Thus, this study was designed to determine that relationship in patients with T2DM without overt cardiovascular disease.

\section{METHODS}

The methods used in this paper are similar to those used in a previously published article [5].

\section{Subjects}

The study enrolled 158 Japanese patients (91 men, 67 women) with T2DM who had been admitted to the metabolic ward of Tagawa Municipal Hospital for glycemic control from October 2013 to March 2017. The diagnosis of T2DM was confirmed according to the criteria of the American Diabetes Association/World Health Organization or by a medical history of diabetes. The study was performed in accordance with the Declaration of Helsinki and approved by the ethics committee of our hospital. Written informed consent was obtained from each patient. Patients with overt heart failure, New York Heart Association Functional Classification greater than I, left ventricular ejection fraction (LVEF) less than 50\%, history of coronary artery disease, severe valvulopathy, chronic atrial fibrillation, or creatinine clearance less than $30 \mathrm{ml} / \mathrm{min}$, and those receiving insulin treatment, were excluded.

All patients underwent clinical evaluation, laboratory assessment, and echocardiographic examination. Body mass index was calculated as weight in kilograms divided by height in meters squared. Concentrations of serum bilirubin, fasting plasma glucose, hemoglobin A1c (HbA1c), immunoreactive insulin, total cholesterol, high-density lipoprotein cholesterol (HDL-C), triglyceride (TG), uric acid, creatinine, and urinary albumin, as well as creatinine clearance, were measured. Initially, HbA1c levels were determined using the criteria of the Japanese Diabetes Society. These concentrations were converted to National Glycohemoglobin Standardization Program concentrations by adding $0.4 \%$ to the Japanese Diabetes Society concentrations [6].

\section{Echocardiography}

All echocardiographic examinations were performed with the Vivid E9 cardiovascular ultrasound machine (GE Healthcare, Chicago, IL, USA). The overall single-dimensional left ventricular measurements and the two-dimensional views were obtained according to the recommendations of the American Society of Echocardiography [7]. We used the Devereux modified cube formula to calculate left ventricular mass (LVM) [8]. To account for gender and body size variations, left ventricular mass was indexed to height ${ }^{2.7}$, with a boundary of $51 \mathrm{~g} / \mathrm{m}^{2.7}$ to define left ventricular hypertrophy in both genders [9]. Relative wall thickness (RWT) was calculated as twice the posterior wall thickness (PW) divided by the left ventricle diastolic diameter. It was considered increased when greater than 0.42 [10]. RWT and left ventricular mass index (LVMI) were used to characterize left ventricular geometry as normal (i.e., normal LVMI and normal RWT), 
concentric remodeling (normal LVMI and increased RWT), concentric hypertrophy (increased LVMI and increased RWT), and eccentric hypertrophy (increased LVMI and normal RWT). All measurements were made by experienced physicians who were blinded to patients' clinical data and outcomes.

\section{Statistical Analysis}

All statistical analyses were performed using JMP statistical software, Version 13 (SAS Institute Inc., Cary, NC, USA). For univariate analysis of the relationship of each parameter with serum bilirubin concentration, RWT and LVMI, continuous variables were analyzed using Spearman's rank correlation and categorical variables using the Mann-Whitney $U$ test. Variables significant in the univariate model were entered into a multivariate linear regression analysis. Continuous variables that were not normally distributed according to the Kolmogorov-Smirnov test were logarithmically transformed. Categorical variables of left ventricular geometry were analyzed via the Chi square test, using Fisher's exact test. Continuous variables were presented as median and interquartile range (IQR) and categorical variables as absolute number (\%). A $P$ value less than 0.05 was considered statistically significant.

\section{RESULTS}

The clinical, anthropometric, and metabolic characteristics of the study groups are shown in Table 1 . The study cohort consisted of 91 men and 67 women, with median age 63 years (IQR $54-69$ years), median body mass index $25.0 \mathrm{~kg} /$ $\mathrm{m}^{2}$ (IQR $22.1-28.4 \mathrm{~kg} / \mathrm{m}^{2}$ ), and median duration of diabetes 8 years (IQR 2-14 years). Median systolic blood pressure (SBP) and diastolic blood pressure (DBP) were 130 (IQR 120-144) and $78 \mathrm{mmHg}$ (IQR 70-87 $\mathrm{mmHg}$ ), respectively. Fasting plasma glucose and HbA1c were $160 \mathrm{mg} / \mathrm{dl}$ (IQR 126-217 mg/dl) and 9.5\% (IQR 8.4-11.5\%). Serum bilirubin concentration and urinary albumin were $0.8 \mathrm{mg} / \mathrm{dl}$ (IQR $0.6-0.9 \mathrm{mg} / \mathrm{dl}$ ) and $12.6 \mathrm{mg} /$ day (IQR
Table 1 Demographic and clinical characteristics of patient cohort $(N=158)$

\begin{tabular}{|c|c|}
\hline \multicolumn{2}{|l|}{ Patient characteristics } \\
\hline Age (years) & $63(54-69)$ \\
\hline Sex, male/female (\%) & $91(57.6) / 67(42.4)$ \\
\hline Body mass index $\left(\mathrm{kg} / \mathrm{m}^{2}\right)$ & $25.0(22.1-28.4)$ \\
\hline Duration of diabetes (years) & $8(2-14)$ \\
\hline SBP (mmHg) & $130(120-144)$ \\
\hline $\mathrm{DBP}(\mathrm{mmHg})$ & $78(70-87)$ \\
\hline Fasting plasma glucose $(\mathrm{mg} / \mathrm{dl})$ & $160(126-217)$ \\
\hline HbAlc (\%) & $9.5(8.4-11.5)$ \\
\hline Fasting insulin $(\mu \mathrm{U} / \mathrm{ml})$ & $4.7(3.2-7.6)$ \\
\hline Total cholesterol (mg/dl) & $191(167-219)$ \\
\hline HDL-C (mg/dl) & $46(38-56)$ \\
\hline $\mathrm{TG}(\mathrm{mg} / \mathrm{dl})$ & $134(102-200)$ \\
\hline Uric acid (mg/dl) & $5.2(4.2-6.3)$ \\
\hline Bilirubin $(\mathrm{mg} / \mathrm{dl})$ & $0.8(0.6-0.9)$ \\
\hline Creatinine $(\mathrm{mg} / \mathrm{dl})$ & $0.68(0.58-0.83)$ \\
\hline Creatinine clearance $(\mathrm{ml} / \mathrm{min})$ & $94.6(75.8-119.7)$ \\
\hline Urinary albumin (mg/day) & $12.6(6.8-44.4)$ \\
\hline \multicolumn{2}{|l|}{ Echocardiography } \\
\hline IVS (mm) & $9(8-10)$ \\
\hline $\mathrm{PW}(\mathrm{mm})$ & $9(8-10)$ \\
\hline LVMI $\left(\mathrm{g} / \mathrm{m}^{2.7}\right)$ & $80(71-92)$ \\
\hline RWT & $0.39(0.36-0.41)$ \\
\hline LVEF (\%) & $67(64-71)$ \\
\hline \multicolumn{2}{|l|}{ Diabetes treatment } \\
\hline Sulfonylurea (\%) & $67(42.4)$ \\
\hline Glinide (\%) & $3(1.9)$ \\
\hline Biguanide (\%) & $45(28.5)$ \\
\hline Thiazolidinedione (\%) & $16(10.1)$ \\
\hline$\alpha$-glucosidase inhibitor (\%) & $26(16.5)$ \\
\hline DPP-4 inhibitor (\%) & $82(51.9)$ \\
\hline SGLT2 inhibitor (\%) & $4(2.5)$ \\
\hline GLP-1 receptor analogue (\%) & $5(3.2)$ \\
\hline
\end{tabular}


Table 1 continued

\begin{tabular}{ll}
\hline Patient characteristics & \\
\hline Other treatment & $2(1.3)$ \\
ACE inhibitor (\%) & $54(34.2)$ \\
ARB (\%) & $2(1.3)$ \\
$\beta$-blocker (\%) & $53(33.5)$ \\
Statin (\%)
\end{tabular}

Categorical variables are presented as number (\%) or median (lower quartile-upper quartile)

$D B P$ diastolic blood pressure, $\mathrm{Hb} A 1 \mathrm{lc}$ hemoglobin Alc, $H D L-C$ high-density lipoprotein cholesterol, IVS interventricular septum thickness, $L V E F$ left ventricular ejection fraction LVMI, left ventricular mass index, $P W$ posterior wall thickness, $R W T$ relative wall thickness, $S B P$ systolic blood pressure, $T G$ triglyceride, $D P P-4$ dipeptidyl peptidase-4, $S G L T 2$ sodium glucose cotransporter 2, GLP1 glucagon-like peptide-1, $A C E$ angiotensin-converting enzyme, $A R B$ angiotensin II receptor blocker

6.8-44.4 mg/day). Echocardiographic data showed that interventricular septum thickness (IVS), PW, LVMI, RWT, and LVEF were $9 \mathrm{~mm}$ (IQR $8-10 \mathrm{~mm}$ ), $9 \mathrm{~mm}$ (IQR $8-10 \mathrm{~mm}$ ), $80 \mathrm{~g} /$ $\mathrm{m}^{2.7}$ (IQR 71-92 $\mathrm{g} / \mathrm{m}^{2.7}$ ), 0.39 (IQR 0.36-0.41), and $67 \%$ (IQR 64-71\%), respectively. With respect to diabetes treatment, $42.4 \%$ of enrolled patients were treated with sulfonylurea, $1.9 \%$ were treated with glinide, $28.5 \%$ were treated with biguanide, $10.1 \%$ were treated with thiazolidinedione, $16.5 \%$ were treated with $\alpha$-glucosidase inhibitor, $51.9 \%$ were treated with dipeptidyl peptidase- 4 inhibitor, $2.5 \%$ were treated with sodium glucose cotransporter-2 inhibitor, and $3.2 \%$ were treated with glucagonlike peptide-1 receptor analogue. With respect to treatment of hypertension and dyslipidemia, $1.3 \%$ of enrolled patients were treated with angiotensin-converting enzyme (ACE) inhibitor, $34.2 \%$ were treated with angiotensin II receptor blocker (ARB), 1.3\% were treated with $\beta$-blocker, and $33.5 \%$ were treated with statin.

The relationships between serum bilirubin concentration and other variables are shown in
Table 2 Correlation between serum bilirubin level and other variables

\begin{tabular}{|c|c|c|}
\hline Variables & $\rho$ & $P$ value \\
\hline Age & -0.074 & 0.354 \\
\hline Sex, female & & 0.492 \\
\hline Body mass index & -0.001 & 0.996 \\
\hline Duration of diabetes & -0.115 & 0.149 \\
\hline SBP & -0.126 & 0.115 \\
\hline DBP & -0.036 & 0.649 \\
\hline Fasting plasma glucose & 0.088 & 0.269 \\
\hline $\mathrm{HbAlc}$ & -0.066 & 0.410 \\
\hline Fasting insulin & -0.096 & 0.228 \\
\hline Total cholesterol & -0.053 & 0.513 \\
\hline HDL-C & 0.249 & 0.002 \\
\hline TG & -0.182 & 0.022 \\
\hline Uric acid & -0.083 & 0.301 \\
\hline Creatinine & -0.064 & 0.425 \\
\hline Creatinine clearance & 0.253 & 0.001 \\
\hline Urinary albumin & -0.144 & 0.070 \\
\hline \multicolumn{3}{|l|}{ Echocardiography } \\
\hline IVS (mm) & -0.153 & 0.055 \\
\hline $\mathrm{PW}(\mathrm{mm})$ & -0.226 & 0.004 \\
\hline $\operatorname{LVMI}\left(\mathrm{g} / \mathrm{m}^{2.7}\right)$ & -0.131 & 0.102 \\
\hline RWT & -0.207 & 0.009 \\
\hline LVEF (\%) & -0.104 & 0.193 \\
\hline
\end{tabular}

$P$ values were calculated using Spearman's rank correlation test or the Mann-Whitney $U$ test, as appropriate

$D B P$ diastolic blood pressure, HbAlc hemoglobin Alc, $H D L-C$ high-density lipoprotein cholesterol, IVS interventricular septum thickness, $L V E F$ left ventricular ejection fraction LVMI, left ventricular mass index, $P W$ posterior wall thickness, $R W T$ relative wall thickness, $S B P$ systolic blood pressure, $T G$ triglyceride

Table 2. HDL-C and creatinine clearance were positively associated with serum bilirubin concentration. TG, PW, and RWT were inversely associated with serum bilirubin concentration. 
There was no association between LVMI and serum bilirubin concentration. Additionally, medication statuses of diabetes, hypertension, and dyslipidemia did not affect left ventricular geometry (Supplemental Table 1). Next, we analyzed the relationships between RWT and other variables. Univariate analyses showed that RWT was significantly correlated with DBP $(P=0.003)$, HbA1c $(P=0.024)$, total cholesterol $(P=0.043)$, urinary albumin $(P=0.023)$, and serum bilirubin concentration $(P=0.009)$ (Table 3). A multivariate linear regression analysis that included the factors significant on univariate analysis was performed to identify

Table 3 Univariate analysis of factors associated with RWT

\begin{tabular}{|c|c|c|}
\hline Variables & $\rho$ & $P$ value \\
\hline Age & 0.007 & 0.933 \\
\hline Sex & & 0.646 \\
\hline Body mass index & 0.063 & 0.435 \\
\hline Duration of diabetes & 0.023 & 0.778 \\
\hline SBP & 0.033 & 0.678 \\
\hline $\mathrm{DBP}$ & 0.235 & 0.003 \\
\hline Fasting plasma glucose & 0.094 & 0.241 \\
\hline HbAlc & 0.180 & 0.024 \\
\hline Fasting insulin & 0.069 & 0.390 \\
\hline Total cholesterol & 0.161 & 0.043 \\
\hline HDL-C & -0.044 & 0.580 \\
\hline TG & 0.096 & 0.231 \\
\hline Uric acid & -0.053 & 0.506 \\
\hline Creatinine & -0.040 & 0.615 \\
\hline Creatinine clearance & -0.085 & 0.286 \\
\hline Urinary albumin & 0.181 & 0.023 \\
\hline Bilirubin & -0.207 & 0.009 \\
\hline
\end{tabular}

$P$ values were calculated using Spearman's rank correlation test or the Mann-Whitney $U$ test, as appropriate

$D B P$ diastolic blood pressure, $H b A l c$ hemoglobin Alc, $H D L-C$ high-density lipoprotein cholesterol, $R W T$ relative wall thickness, $S B P$ systolic blood pressure, $T G$ triglyceride parameters independently associated with RWT (Table 4). This analysis showed that log RWT was positively correlated with DBP $(P=0.010)$ and that log RWT was inversely correlated with $\log$ bilirubin $(P=0.003)$. The median bilirubin concentration was $0.8 \mathrm{mg} / \mathrm{dl}$, so we divided the patients into two groups and analyzed the association of left ventricular geometry with bilirubin concentration. The patients with lower bilirubin had a relatively high risk of concentric remodeling compared with the patients having higher bilirubin at a prevalence of $16.4 \%$ vs. $3.5 \%(P=0.007)$. The prevalence of normal geometry, eccentric hypertrophy, and concentric hypertrophy were comparable between the lower vs. higher bilirubin groups (32.9\%, $35.6 \%$, and $15.1 \%$ vs. $45.9 \%, 41.2 \%$, and $9.4 \%, P=0.106, P=0.515$, and $P=0.331$ respectively) (Fig. 1). These findings suggest that low bilirubin concentration may be a risk factor for the progression of concentric remodeling in patients with T2DM.

\section{DISCUSSION}

Diabetes mellitus is associated with concentric left ventricular remodeling [11], which is an adverse prognostic marker for cardiovascular events [12] and is linked to contractile dysfunction [13]. In the present study, we showed that RWT significantly and inversely correlated with serum bilirubin concentration and that the patients with low bilirubin concentrations had a high prevalence of concentric remodeling.

Table 4 Multivariate linear regression analysis of factors associated with $\log$ RWT

\begin{tabular}{lcc}
\hline Variables & \multicolumn{1}{l}{$\boldsymbol{\rho}$} & $\boldsymbol{P}$ value \\
\hline DBP & 0.20 & 0.010 \\
Log HbAlc & 0.08 & 0.272 \\
Log total cholesterol & 0.04 & 0.552 \\
Log urinary albumin & 0.07 & 0.409 \\
Log bilirubin & -0.23 & 0.003 \\
\hline
\end{tabular}

$D B P$ diastolic blood pressure, $H b A l c$ hemoglobin Alc, $R W T$ relative wall thickness 


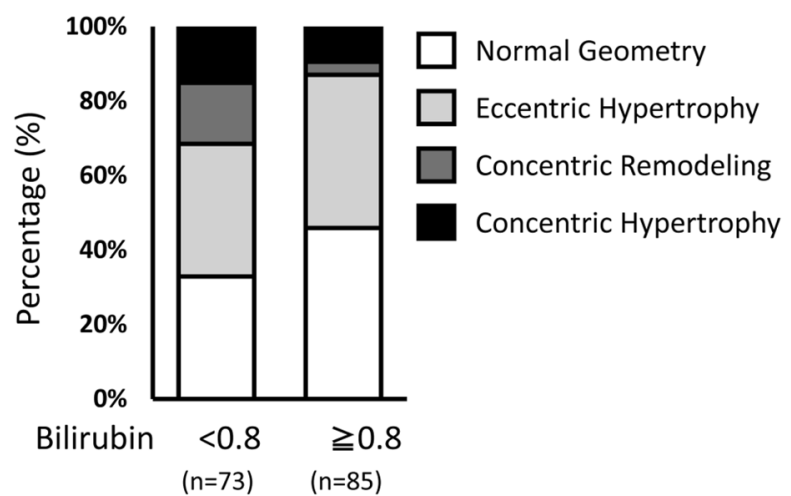

Fig. 1 Left ventricular geometry patterns in lower vs. higher bilirubin groups

Bilirubin is an end-product of heme catabolism and has long been used in clinical practice as a marker for hepatobiliary and hematopoietic diseases. Furthermore, bilirubin has been recognized for many years as an endogenous antioxidant [14]. Oxidative stress is an important pathogenic factor in the development of diabetic vascular complications, including cardiomyopathy [15-17]. In addition, suppressing oxidative stress in vivo was reported to prevent diabetic cardiomyopathy [18, 19]. Previously, we showed a significantly lower prevalence of cardiovascular disease in diabetic patients with Gilbert's syndrome, a congenital hyperbilirubinemia, along with reduced markers of oxidative stress and inflammation [20]. Strong evidence supports an association between cardiac remodeling and oxidative stress resulting from increased reactive species production and decreased antioxidant defense [21]. Taken together, bilirubin may have a protective role in the progression of concentric remodeling via suppressing oxidative stress in the patients with T2DM.

The clinical and experimental evidence suggests that the renin-angiotensin-aldosterone system and sympathetic nervous system also play an important role in the process of cardiac remodeling [21]. In addition, ACE inhibitors, $\beta$ blockers, and ARBs have been consistently shown to decrease remodeling in animal model
[22-25]. These findings have been validated in clinical trials, and these drugs are currently indicated for patients with an ejection fraction of less than $40 \%[21,25]$. However, these medication statuses did not affect left ventricular geometry in the present study. The reason may be that the patients with overt cardiovascular disease were excluded and that few patients took ACE inhibitors or $\beta$-blockers in this study. Additionally, a previous study showed that serum bilirubin concentrations were inversely correlated with LVMI in the patients with hypertension who had not received any treatment [26]. In that study, hypertensive patients with diabetes mellitus were excluded. Compared with their study, the blood pressure of patients enrolled in our study was controlled by antihypertensive medications. For these reasons, there may be no association between LVMI and serum bilirubin concentrations in our study. Additional studies are required to evaluate these correlations in detail.

One limitation of our study was its crosssectional design. Therefore, a cause-and-effect relationship could not be determined. Another limitation was the uncertainty of the diagnosis of ischemic heart disease. Ischemic heart disease was excluded on the basis only on the absence of symptoms, the lack of previous cardiovascular disease, and electrocardiogram results, indications that may not completely rule out ischemic heart disease. Additionally, the number of participants was relatively small. Further study with a large cohort is necessary for showing stronger correlation.

\section{CONCLUSION}

This study showed for the first time that serum bilirubin concentrations were inversely correlated with RWT and that the patients with low bilirubin concentrations had a higher prevalence of concentric left ventricular remodeling. Low bilirubin concentrations may be a risk factor for the progression of concentric remodeling in patients with T2DM. 


\section{ACKNOWLEDGEMENTS}

Funding. No funding or sponsorship was received for this study or publication of this article. The article processing charges were funded by the authors.

Contributions. Tomoaki Inoue wrote the manuscript and researched the data. Noriyuki Sonoda contributed to the discussion and reviewed/edited the manuscript. Shinsuke Hiramatsu, Shinichiro Kimura, Yoshihiro Ogawa, and Toyoshi Inoguchi provided advice on the interpretation of the results. Tomoaki Inoue is the guarantor of this work and, as such, had full access to all the data in the study. Tomoaki Inoue also takes responsibility for the integrity of the data and the accuracy of the data analysis.

Authorship. All named authors meet the International Committee of Medical Journal Editors (ICMJE) criteria for authorship for this manuscript, take responsibility for the integrity of the work as a whole, and have given final approval for the version to be published.

Disclosures. Tomoaki Inoue, Noriyuki Sonoda, Shinsuke Hiramatsu, Shinichiro Kimura, Yoshihiro Ogawa, and Toyoshi Inoguchi have nothing to disclose.

Compliance with Ethics Guidelines. This article is compliant with all the ethical guidelines and permission was obtained from the institutional ethical committee for the study. All procedures followed were in accordance with the ethical standards of the responsible committee on human experimentation (institutional and national) and with the Helsinki Declaration of 1964, as revised in 2013. Informed consent was obtained from all patients for being included in the study.

Data Availability. The datasets generated during and/or analyzed during the current study are available from the corresponding author on reasonable request.
Open Access. This article is distributed under the terms of the Creative Commons Attribution-NonCommercial 4.0 International License (http://creativecommons.org/licenses/ by-nc/4.0/), which permits any noncommercial use, distribution, and reproduction in any medium, provided you give appropriate credit to the original author(s) and the source, provide a link to the Creative Commons license, and indicate if changes were made.

\section{REFERENCES}

1. Grundy SM, Benjamin IJ, Burke GL, et al. Diabetes and cardiovascular disease: a statement for healthcare professionals from the American Heart Association. Circulation. 1999;100:1134-46.

2. Schwertner HA, Jackson WG, Tolan G. Association of low serum concentration of bilirubin with increased risk of coronary artery disease. Clin Chem. 1994;40:18-23.

3. Breimer LH, Wannamethee G, Ebrahim S, Shaper AG. Serum bilirubin and risk of ischemic heart disease in middle-aged British men. Clin Chem. 1995;41:1504-8.

4. Djousse L, Levy D, Cupples LA, et al. Total serum bilirubin and risk of cardiovascular disease in the Framingham offspring study. Am J Cardiol. 2001;87:1196-200.

5. Inoue $\mathrm{T}$, Maeda $\mathrm{Y}$, Sonoda $\mathrm{N}$, et al. Hyperinsulinemia and sulfonylurea use are independently associated with left ventricular diastolic dysfunction in patients with type 2 diabetes mellitus with suboptimal blood glucose control. BMJ Open Diabetes Res Care. 2016;4:e000223.

6. Kashiwagi A, Kasuga M, Araki E, et al. International clinical harmonization of glycated hemoglobin in Japan: from Japan Diabetes Society to National Glycohemoglobin Standardization Program values. J Diabetes Investig. 2012;3:39-40.

7. Lang RM, Bierig M, Devereux RB, et al. Recommendations for chamber quantification: a report from the American Society of Echocardiography's Guidelines and Standards Committee and the Chamber Quantification Writing Group, developed in conjunction with the European Association of Echocardiography, a branch of the European Society of Cardiology. J Am Soc Echocardiogr. 2005;18:1440-63. 
8. Devereux RB, Alonso DR, Lutas EM, et al. Echocardiographic assessment of left ventricular hypertrophy: comparison to necropsy findings. Am J Cardiol. 1986;57:450-8.

9. de Simone G, Daniels SR, Devereux RB, et al. Left ventricular mass and body size in normotensive children and adults: assessment of allometric relations and impact of overweight. J Am Coll Cardiol. 1992;20:1251-60.

10. Lang RM, Badano LP, Mor-Avi V, et al. Recommendations for cardiac chamber quantification by echocardiography in adults: an update from the American Society of Echocardiography and the European Association of Cardiovascular Imaging. Eur Heart J Cardiovasc Imaging. 2015;16:233-70.

11. Levelt E, Mahmod M, Piechnik SK, et al. Relationship between left ventricular structural and metabolic remodeling in type 2 diabetes. Diabetes. 2016;65:44-52.

12. Verdecchia P, Schillaci G, Borgioni C, et al. Prognostic value of left ventricular mass and geometry in systemic hypertension with left ventricular hypertrophy. Am J Cardiol. 1996;78:197-202.

13. Rosen BD, Edvardsen T, Lai S, et al. Left ventricular concentric remodeling is associated with decreased global and regional systolic function: the MultiEthnic Study of Atherosclerosis. Circulation. 2005;112:984-91.

14. Stocker R, Yamamoto Y, McDonagh AF, Glazer AN, Ames BN. Bilirubin is an antioxidant of possible physiological importance. Science. 1987;235:1043-6.

15. Baynes JW. Role of oxidative stress in development of complications in diabetes. Diabetes. 1991;40:405-12.

16. Kajstura J, Fiordaliso F, Andreoli AM, et al. IGF-1 overexpression inhibits the development of diabetic cardiomyopathy and angiotensin II-mediated oxidative stress. Diabetes. 2001;50:1414-24.

17. Crespo MJ, Zalacain J, Dunbar DC, Cruz N, Arocho L. Cardiac oxidative stress is elevated at the onset of dilated cardiomyopathy in streptozotocin-diabetic rats. J Cardiovasc Pharmacol Ther. 2008;13:64-71.

18. Cai L, Wang Y, Zhou G, et al. Attenuation by metallothionein of early cardiac cell death via suppression of mitochondrial oxidative stress results in a prevention of diabetic cardiomyopathy. J Am Coll Cardiol. 2006;48:1688-97.

19. Li CJ, Zhang QM, Li MZ, et al. Attenuation of myocardial apoptosis by alpha-lipoic acid through suppression of mitochondrial oxidative stress to reduce diabetic cardiomyopathy. Chin Med J (Engl). 2009;122:2580-6.

20. Inoguchi T, Sasaki S, Kobayashi K, Takayanagi R, Yamada T. Relationship between Gilbert syndrome and prevalence of vascular complications in patients with diabetes. JAMA. 2007;298:1398-400.

21. Azevedo PS, Polegato BF, Minicucci MF, Paiva SA, Zornoff LA. Cardiac remodeling: concepts, clinical impact, pathophysiological mechanisms and pharmacologic treatment. Arq Bras Cardiol. 2016;106:62-9.

22. Sayer G, Bhat G. The renin-angiotensin-aldosterone system and heart failure. Cardiol Clin. 2014;32:21-32.

23. Albuquerque FN, Brandao AA, Silva DA, et al. Angiotensin-converting enzyme genetic polymorphism: its impact on cardiac remodeling. Arq Bras Cardiol. 2014;102:70-9.

24. Florea VG, Cohn JN. The autonomic nervous system and heart failure. Circ Res. 2014;114:1815-26.

25. Reis Filho JR, Cardoso JN, Cardoso CM, PereiraBarretto AC. Reverse cardiac remodeling: a marker of better prognosis in heart failure. Arq Bras Cardiol. 2015;104:502-6.

26. Zhou T, Chen X, Li Z, Li L. Relationship between serum bilirubin and left ventricular hypertrophy in patients with essential hypertension. PLoS One. 2015;10:e0125275. 